\title{
Evaluation of potential eye or skin irritation/corrosion in rabbit exposed to $\mathrm{TiO} 2$ photocatalyst (GST)
}

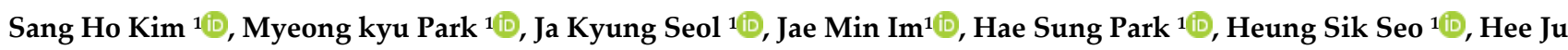 \\ Park ${ }^{2}$, Sung Soon $\mathrm{Nah}^{3, *(i)}$ \begin{abstract}
Jeollanam-do, 58141, Republic of Korea
${ }^{2}$ Research Laboratory, Bentech Frontier Co. Ltd., Nanosandan-ro, Nam-myeon, Jangseong, Jeollanam-do, 57248, Republic of Korea

${ }^{3}$ Division of Environment \& Health, Korea Testing \& Research Institute, 98, Gyoyukwon-ro, Gwacheon-si, Gyeonggi-do, 13810, Republic of Korea

*Correspondence: $\underline{\text { nahs@ktr.or.kr }}$
\end{abstract} \\ ${ }^{1}$ Healthcare Research Institute, Korea Testing and Research Institute (KTR), 12-63, Sandan-gil, Hwasun-eup, Hwasun-gun,
}

Received: November 16, 2020 Accepted: September 10, 2021

\begin{abstract}
$\mathrm{TiO}_{2}$ NPs photocatalyst is widely used in a variety of applications and products in the environmental and energy fields, including self-cleaning surfaces, air and water purification systems, sterilization, hydrogen evolution, and photoelectrochemical conversion. The possible biological and safety effects of $\mathrm{TiO}_{2}$ dermal exposure and absorption have not been well studied and more investigations on the potential health hazards of the $\mathrm{TiO}_{2}$ are needed. This study aimed to investigate potential effect of local lesions (eye and skin irritation/corrosion) for new $\mathrm{TiO}_{2}$ material powder, GST produced through sludge recycling of the sewage treatment plant in according to the OECD test guideline (TG 404, 405) and imaging evaluation (micro-computed tomography analysis), histopathology examination. Also, P-25, commercial photocatalyst was used to compare with GST. For the eye or skin irritation/corrosion test, the test substances (GST, P-25) showed no irritation/corrosion for local lesions and the GHS category was identified as a "No hazard class". The imaging analysis indicated that GST did not penetrate or distribute in the local lesions (eye, skin) and the treatmentrelated effect was not observed in histopathology. Therefore, the present study revealed that new $\mathrm{TiO}_{2}$ powder, GST was considered to be no potential effects (irritation/corrosion), penetration or distribution in the local lesions (eye, skin).
\end{abstract}

Keywords: Skin, Eye, Irritation, Corrosion, $\mathrm{TiO}_{2}$, GST

\section{Introduction}

$\mathrm{TiO}_{2}$ (Titanium Dioxide) photocatalyst, which rarely interacts with other chemical substances to undergo a reaction which can change its own chemical composition or the chemical milieu of the surrounding environment, is widely used in a variety of applications and products in the environmental and energy fields, including self-cleaning surfaces, air and water purification systems, sterilization, hydrogen evolution, and photo-electrochemical conversion. It is often used in the cosmetic (sunscreen, etc.), pharmaceutical, paint and paper industries. One of the main differences between $\mathrm{TiO}_{2}$ nanoparticles (NPs) and conventional $\mathrm{TiO}_{2}$ is the much greater surface area of a given mass or volume of nanoparticles compared to an equivalent mass or volume of conventional $\mathrm{TiO}_{2}$ particles. This greater relative surface area of the $\mathrm{TiO}_{2} \mathrm{NPs}$ affords a greater potential for properties such as catalytic activity and UV absorption at certain wavelengths. Such properties have led to the development or use of $\mathrm{TiO}_{2} \mathrm{NPs}$ for a wide variety of applications, and due to changes of dimension, $\mathrm{TiO}_{2}$ NPs may show different biological, chemical, optical, magnetic and structural properties and may induce differential toxicity [1]. The possible biological and safety effects of $\mathrm{TiO}_{2} \mathrm{NPs}$ for dermal exposure and absorption have not been well studied and more investigations on the potential health hazards of the $\mathrm{TiO}_{2}$ nanoparticles are needed [2]. The exposure can be incidental or intentional. One of the possible effects of chemical substances with human exposures is eye and skin irritation. Especially, the skin is the largest organ of the body and can be an important route for the entry of NPs into mammals [3].

In general, the physiological response to a chemical stimulus is irritation, which involves objective changes (e.g., local redness and oedema) and subjective sensations (e.g., pruritus and pain). Assessment of eye and skin irritation potential is an important part of any comprehensive toxicology programme for new chemicals and consumer products, and it is essential to ensuring the safety of individuals. Therefore, before humans can be exposed to such substances, the tendency 
of new chemicals to cause eye and skin irritation must be determined. In several studies for $\mathrm{TiO}_{2} \mathrm{NPs}_{\mathrm{s}}$ Sadrieh et al. showed no significant penetration through the in-tact skin and Bennat et al found that $\mathrm{TiO}_{2} \mathrm{NPs}_{\text {can }}$ penetrate through hairy skin on application as oil-in-water emulsion ( $5 \%$ NPs to human skin with the size of $20 \mathrm{~nm}$ ). Also, the acute test on dermal, eye and vaginal mucous membrane in mice showed no significant irritation [4-6]. Also, $\mathrm{TiO}_{2}$ nanoparticles do not induce phototoxicity, acute skin irritation, or skin sensitization [7]. In the study using 3D human skin model (KeraSkin $\left.{ }^{\mathrm{TM}}\right)$ after application of NPs (final concentration of $25 \%$ ), there was no skin irritation [8].

To evaluate the toxicological effects in local treatment, the image-based method could be used to identify of chemical; micro-computer tomography (micro-CT), magnetic resonance imaging (MRI), optical tomography, fluorescence molecular tomographic imaging [9-10]. Recently, Kim et al. reported that they used micro-CT to investigate the detection of $\mathrm{ZnO}$ NPs in eyes of rats and confirmed association with local distribution in ocular lesions [11].

The $\mathrm{TiO}_{2}$ powder, GST ( $\mathrm{TiO}_{2}$ produced from sludge recycling) was manufactured to have cost-competitive lower than price of commercial material (P-25, Evonik Corp., a flame-made multiphasic $\mathrm{TiO}_{2}$ nanoparticles containing anatase and rutile, as well as a small amount of amorphous $\mathrm{TiO}_{2}$ ) [12-13].

In this study, we examined safety of new $\mathrm{TiO}_{2}$ material photocatalyst (GST) by means of skin or eye irritation/corrosion tests according to OECD test guideline 404 / 405 and compared with P-25, commercial product. Also, we investigated the detection of NPs in the eye/skin lesions using micro-CT analysis and confirmed the local lesions by histopathological examination.

\section{Materials and Methods Test facility}

This study was conducted in compliance with the principles of Good Laboratory Practice (GLP) at KTR (Korea Testing \& Research Institute), Hwasun based on the Korea Good Laboratory Practice (KGLP) and OECD “Principle of Good Laboratory Practice, ENV/MC/CHEM (98)17 (as revised in 1997)". The study protocol was reviewed and approved (IAC2019-2069, 2070, 2429, 2430, IAC2020-2349, 2350) by the Institutional Animal Care and Use Committee (IACUC) of KTR Hwasun based on the Animal Protection Act [Enforcement Date: 2019-08-27] [No.16544 (2019-08-27, partial revision)] [14] and the Laboratory Animal Act [Enforcement Date: 2019-03-12][No. 15944 (2018-12-11, partial revision)] [15]. Also, this study was conducted in accordance with the OECD guidelines for the testing of chemicals, Section 4, TG 404 "acute dermal irritation / corrosion" [16] and TG 405 "acute eye irritation/corrosion" [17].

\section{Animal Husbandry and Maintenance}

This study employed three male rabbits (New Zealand White, 2-3 kg) to test for the eye or skin irritation/corrosion and these were kept carefully following an acclimation period of 6-8 days to ensure their suitability for the study. Test animals were kept within a limited-access rabbit facility with environmental conditions set to a temperature of $20 \pm 3{ }^{\circ} \mathrm{C}$, a humidity of 30-70 \% RH and a 12-h light / 12-h dark cycle. For study, the healthy animals were used after examining body weight changes, healthy condition, and dermal condition.

In addition, two animals ( 1 hour, 24 hours after treatment) were assigned to the test group of $\mathrm{TiO}_{2}$ (GST) for the imaging analysis (micro-CT, histopathology) and histopathological examination; eye and skin, respectively. At this time, eye with accessory gland (including conjunctival sac) and skin with panniculus carnosus was excised without washing for treatment lesion.

\section{Test materials and Preparation}

The GST (pale yellow powder, crystalline composition of $100 \%$ anatase), $\mathrm{TiO}_{2}$ photocatalyst was produced through sludge recycling of the sewage treatment plant and P-25 (crystalline composition of $88 \%$ anatase/ $12 \%$ rutile), commercial nanomaterial product $\mathrm{TiO}_{2}$ (AEROXIDE®, Evonik Industries, Germany) was provided by Bentec Frontier Co., Ltd.

To evaluate of characterization of GST, It was measured about Zeta potential [Particle size \& Zeta potential analyzer (Zetasizer Nano ZSP, Malvern Instruments LTD., UK) in Korea TECH], SEM (scanning electron microscope) particle size image [FE-SEM(Field Emission Scanning Electrong Microscope, Tescan Corp., Czech)] equipped with EDS systems (Thermo scientific, USA) in KRICT (Ulsan department), TEM (Transmission electron microscopy) image [FE-EFTEM (Field Emission Energy Filtered Transmission Electron Microscopy, JEOL, Japan) in Korea Basic Science Institute (Jeonju department)] and size distribution [Image J software (https://imagej.nih.gov/ij/download.html)].

For the test procedure, test substance was moistened with the smallest amount of sterilized distilled water for the skin irritation/corrosion test in accordance with test guidelines. 


\section{Test procedure}

The characterization of GST showed in (Figure 1 and 2), respectively. The zeta potential is known for indicator of the droplet stability, where values more positive than $+30 \mathrm{mV}$ and more negative than $-30 \mathrm{mV}$ indicate good stability against coalescence [18]. The estimated value of GST was a negative value $(-35.4 \mathrm{mV})$ and this value showed that GST had a good stability and was thought to have a less agglomeration nature.

Generally, the nanosubstance was known as a substance that have an extremely small structures of 1 to 100 nanometers. In this study, the particle size value for GST was $95.8 \pm 46.3 \mathrm{~nm}$ (mean \pm standard deviation) and $34.1 \%$ by number of the particles had a diameter $>100 \mathrm{~nm}$ in particle size. The results demonstrated that it was difficult to recognize as nanomaterial because there were distributed in various size.

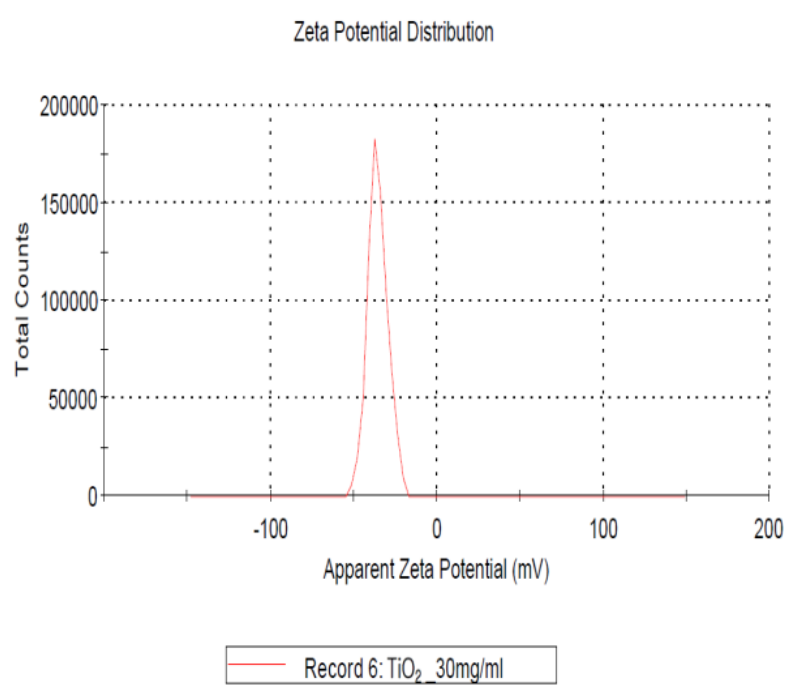

(a)

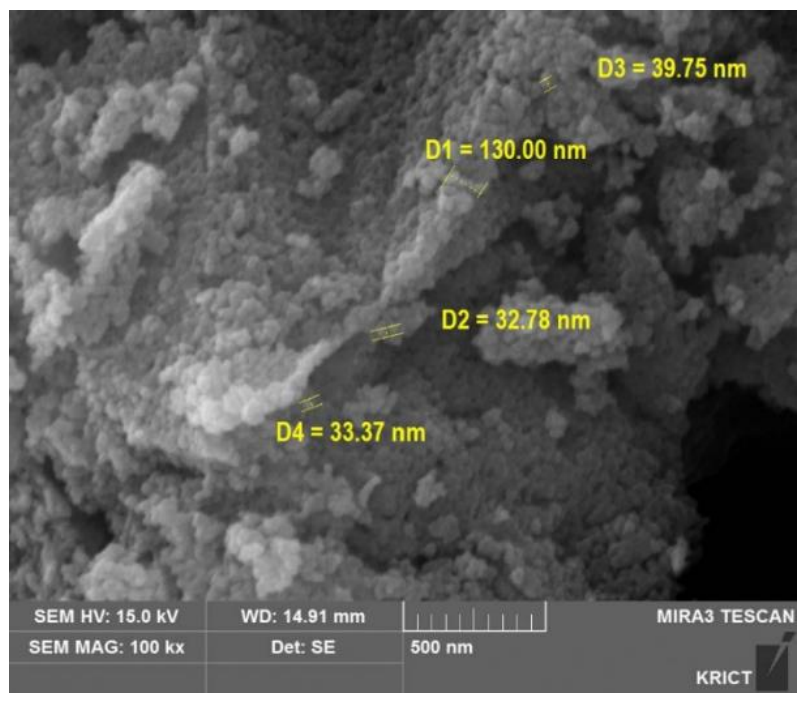

(b)

Figure 1. Characterization of $\mathrm{TiO}_{2}$ particles (GST): (a) Negative zeta potential $(-35.4 \mathrm{mV}, 30 \mathrm{mg} / \mathrm{mL})$; (b) SEM (scanning electron microscope) image.

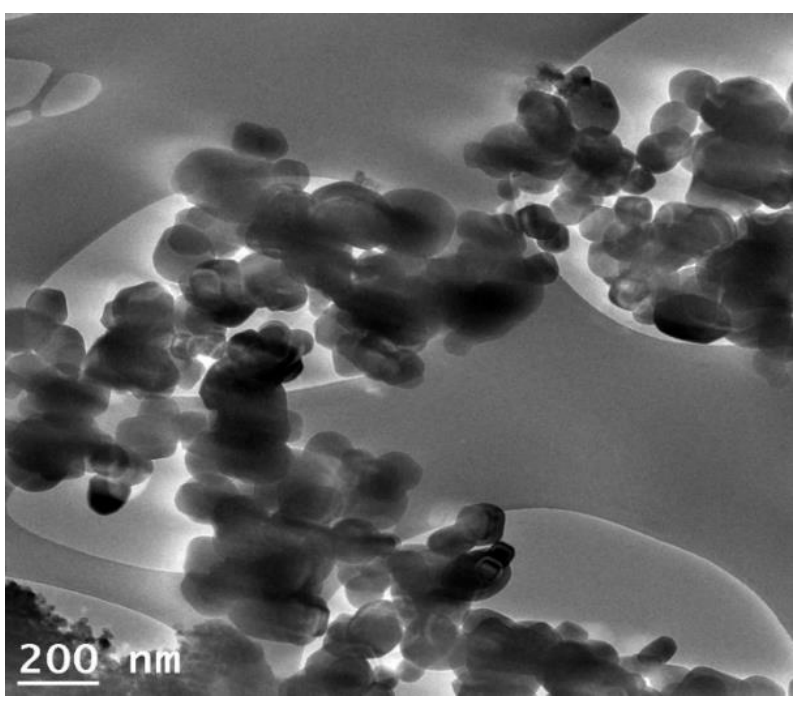

(a)

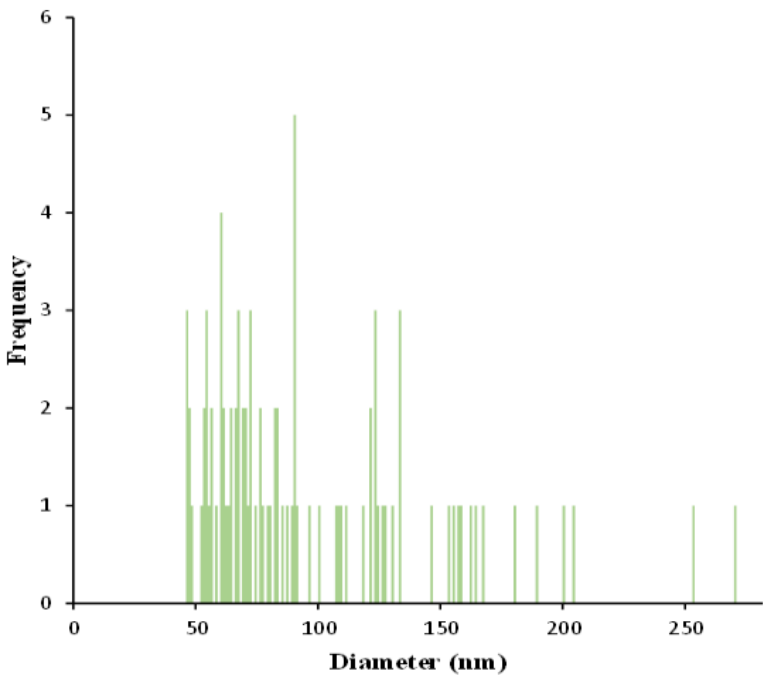

(b)

Figure 2. Characterization of $\mathrm{TiO}_{2}$ particles (GST): (a) A particles dispersed in $99.9 \% \mathrm{EtOH}$ was deposited on a copper grid and analyzed by TEM (Transmission electron microscope) image; (b) Size distribution of the imaged GST.

\section{Eye irritation/corrosion test}

The initial test was conducted on one rabbit and the confirmatory test was conducted to confirm irritant or negative response using two additional animals. Five minutes prior to test substance application, 2 drops of a topical ocular anesthetic ( $0.5 \%$ proparacaine hydrochloride) to minimize pain or distress were applied to each eye and then the test 
substance was applied to the conjunctival sac of the right eye of each animal $(0.1 \mathrm{~g} / \mathrm{animal})$. The left eye was remained unapplied and served as the reference control. The test substance had not been removed from the eye by physiological mechanisms at the first observation time and it was gently washed out with washing solvent (Normal Saline Injection, Daihan Pharm Co., Ltd.) at 24 hours. And then the eye reactions were macroscopically observed at 1, 24, 48 and 72 hours after treatment according to grading of ocular lesions for cornea, iris, conjunctivae and chemosis of OECD test guideline TG 405. The scores for grades at 24,48 and 72 hours were summed and divided by the number of the observations for the treated sites [Mean score: $\sum$ Eye reaction (at 24, 48, 72 hours) / 3]. And then eye irritation/corrosion was categorized according to the GHS category (3.3.1: Serious eye damage/Irreversible effects on the eye category, 3.3.2: Reversible effects on the eye categories) [19].

\section{Skin irritation/corrosion test}

The back of the animals was clipped free of fur with an electric clipper 24 hours before application of the test substance and this area were divided into two sites (treatment / control site) within the same area $\left(6 \mathrm{~cm}^{2}\right)$. A dose of 0.5 $\mathrm{g} /$ site of test substance was moistened with the smallest amount of sterilized distilled water to the gauze patch and was applied to the test site and the untreated skin area was used as the control. The back of rabbit was covered with a nonocclusive bandage for the duration of the exposure period and then the residual test substance was carefully removed by washing away with washing solvent (sterilized distilled water) for observation after removing bandage.

The initial test was conducted on one rabbit and was applied sequentially to the animal for 3 minutes, 1 hour, 4 hours and the confirmatory test was conducted to confirm irritant or negative response using two additional animals and was applied to two animals for 4 hours. The skin reaction was observed for 1, 24, 48 and 72 hours after removal bandage and residual test substance were evaluated according to the scoring system for skin reactions and mean score was evaluated (erythema/eschar and oedema formation). The mean score was calculated as the following: Scores for erythema and oedema at 24, 48 and 72 hours were summed and divided by the number of the observations for the treated sites [Mean score: $\Sigma$ Skin reaction (at 24, 48, 72 hours) / 3]. And then the irritation/corrosion degree was categorized according to the GHS category (3.2.1: Skin corrosion category and sub-categories, 3.2.2: Skin irritation categories) [19].

\section{Micro-CT analysis}

The eyes and skin with adjacent tissue were dissected. After full fixation in $10 \%$ neutral buffered formalin, the tissue specimens in fixative were requested to Center for Non-clinical development (CND) of Asan medical center for microCT analysis. A Skyscan Desktop Micro-CT 1176 (Kartuizersweg 3B, Belgium) instrument, with a source voltage of $50 \mathrm{kV}$, and current of $500 \mu \mathrm{A}$, was used to acquire X-ray radiographs. The specimens were attached to a stage that rotated $360^{\circ}$ with images acquired at $1.0^{\circ}$ intervals. After scanning, cross-sectional slices were reconstructed and each scan result was reconstructed using the $0.010 \sim 0.067$ threshold values to distinguish bone and air. Three-dimensional (3D) analysis was performed using the Skyscan software, CTvox [2.2.0 r762(64-bit)]. The parameters of micro-architecture, including the deposition and distribution of foreign materials in the eyes and skin of rabbit treated with $\mathrm{TiO}_{2} \mathrm{NPs}$ (GST), were evaluated using the built-in micro-CT software [2.2.0 r762(64-bit)].

\section{Histology}

At 1 hour and 24 hours after test substance treatment, the tissues (skin, eye) were fixed in $10 \%$ neutral buffered formalin (BBC Biochemical, USA, Lot No.95922) and then paraffin was embedded, sectioned, and adhered to slides. Sections of each tissue were stained by hematoxylin (BBC Biochemical, USA, Lot No.95925) and eosin (BBC Biochemical, USA, Lot No.959058) to assess tissue morphology. The histopathological observations were performed under light microscopy.

\section{Results and Discussion Eye irritation/corrosion test}

The test substance (GST, P-25) was remained in the conjunctival sac of eye at the time of first (1 hour) observation and it was considered to be non-absorption into the eye.

The eye reactions (irritation or corrosion) were not observed on the eye sites applied P-25 and the mean score of P-25 was " 0.0 " in each rabbit at any time of the observation after removing the test substance (Table 1, Figure 3 and 4 ). In the animals applied with GST, the conjunctivae redness and chemosis swelling were observed on the eye lesion as follows (Table 2, Figure 5 and 6). The conjunctivae redness was observed as score 1 (some blood vessels hyperaemic) at $1,24,48$ hours and was recovered at 72 hours and the mean score was "0.7". The conjunctivae chemosis swelling was observed as score 1 (some selling above normal) at 1 hour and was disappeared at 24 hours and mean score could not be calculated. These results were considered that observed reactions were caused by contact with the test material and was the effect of the test substance. Also, based on the evaluation results, the GHS category was identified as a "No hazard class". From a risk assessment perspective, it is essential to point out that both size-dependent properties and biological effects that are of 
potential concern for human health, specifically toxicokinetic behavior and particle-cell interactions, are not closely related to specific size thresholds.
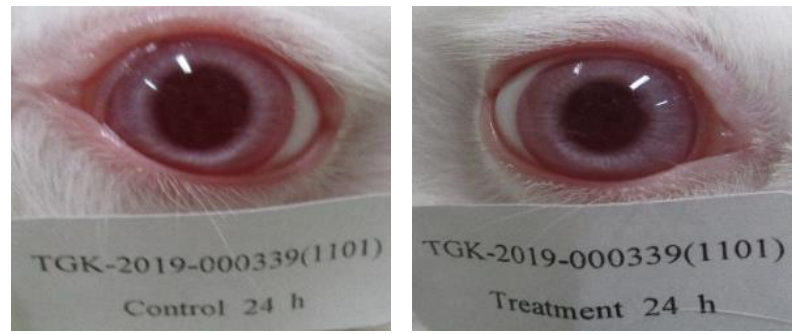

(a)

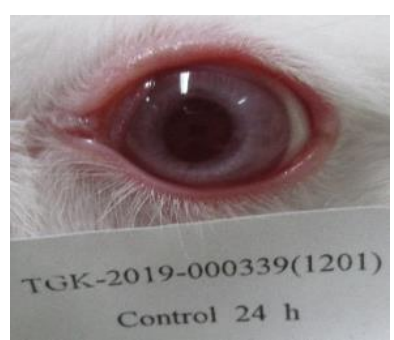

(b)

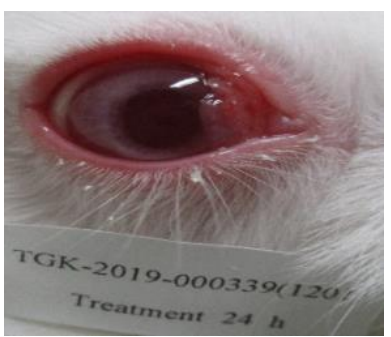

Figure 3. Eye photographs observed at 24 hours after application of test substance, P-25 (No eye reaction): (a) Initial test; (b) Confirmatory test.

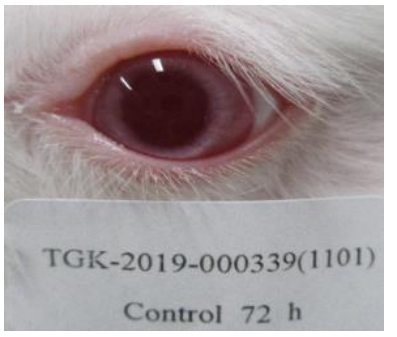

(a)

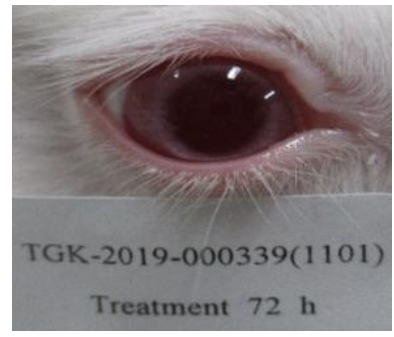

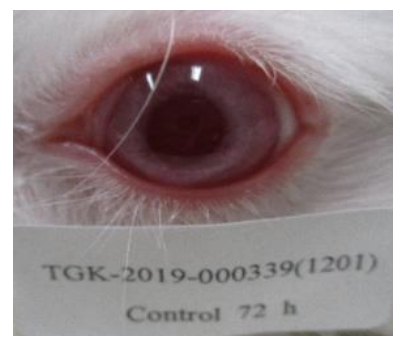

\section{(b)}

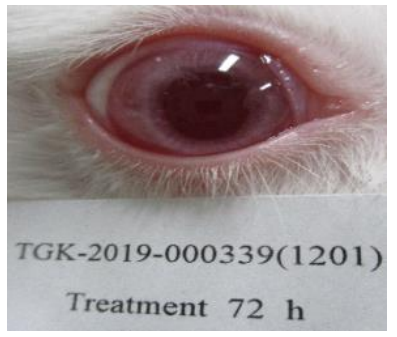

Figure 4. Eye photographs observed at 72 hours after application of test substance, P-25 (No eye reaction): (a) Initial test; (b) Confirmatory test.
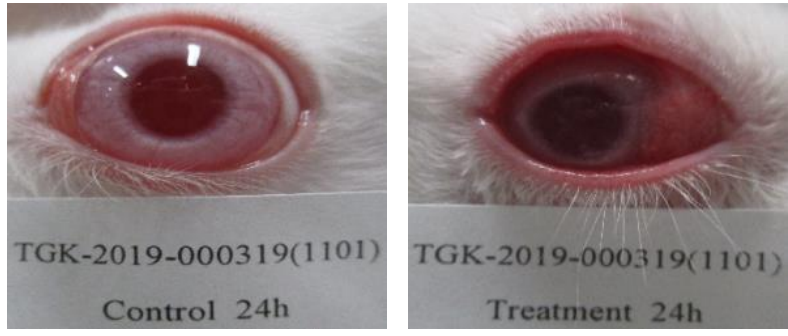

(a)
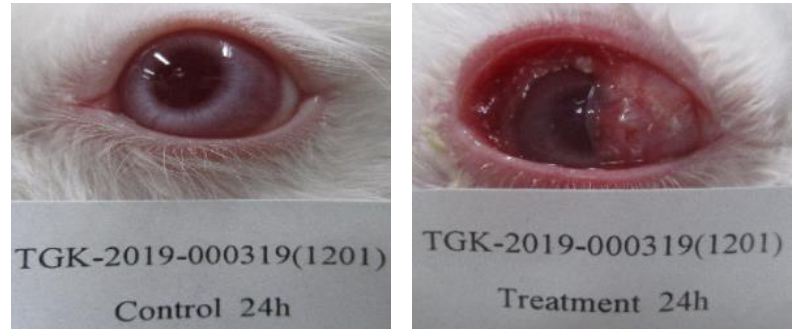

(b)

Figure 5. Eye photographs observed at 24 hours after application of test substance, GST (conjunctivae redness): (a) Initial test; (b) Confirmatory test.
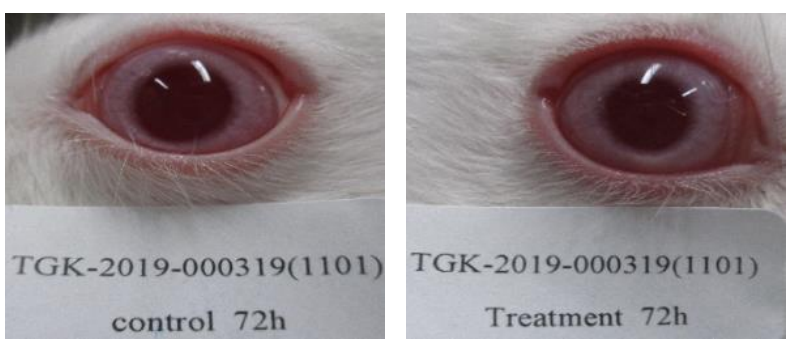

(a)

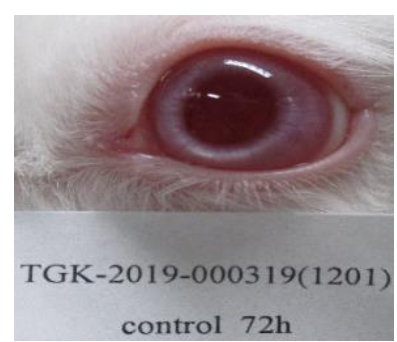

(b)

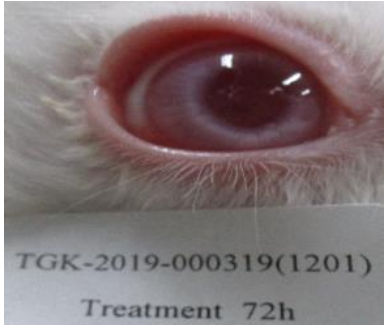

Figure 6. Eye photographs observed at 72 hours after application of test substance, GST (conjunctivae redness was recovered): (a) Initial test; (b) Confirmatory test. 
Table 1. Mean score of eye reaction (P-25)

\begin{tabular}{lllllll}
\hline Group & $\begin{array}{l}\text { Test } \\
\text { substance }\end{array}$ & $\begin{array}{l}\text { Animal } \\
\text { number }\end{array}$ & $\begin{array}{l}\text { Cornea } \\
\text { (Opacity) }\end{array}$ & Iris & $\begin{array}{l}\text { Conjunctivae } \\
\text { (Redness) }\end{array}$ & $\begin{array}{l}\text { Chemosis } \\
\text { (Swelling) }\end{array}$ \\
\hline G1 & & 1101 & 0.0 & 0.0 & 0.0 & 0.0 \\
G2 & P-25 & 1201 & 0.0 & 0.0 & 0.0 & 0.0 \\
& & 1202 & 0.0 & 0.0 & 0.0 & 0.0 \\
\hline
\end{tabular}

G1: Initial test, G2 : Confirmatory test, Mean score : $\sum$ Eye reaction (at 24, 48, 72 hours) / 3

Table 2. Mean score of eye reaction (GST)

\begin{tabular}{lllllll}
\hline Group & $\begin{array}{l}\text { Test } \\
\text { substance }\end{array}$ & $\begin{array}{l}\text { Animal } \\
\text { number }\end{array}$ & $\begin{array}{l}\text { Cornea } \\
\text { (Opacity) }\end{array}$ & Iris & $\begin{array}{l}\text { Conjunctivae } \\
\text { (Redness) }\end{array}$ & $\begin{array}{l}\text { Chemosis } \\
\text { (Swelling) }\end{array}$ \\
\hline G1 & & 1101 & 0.0 & 0.0 & 0.7 & 0.0 \\
G2 & GST & 1201 & 0.0 & 0.0 & 0.7 & 0.0 \\
& & 1202 & 0.0 & 0.0 & 0.7 & 0.0 \\
\hline
\end{tabular}

G1: Initial test, G2 : Confirmatory test, Mean score : $\sum$ Eye reaction (at 24, 48, 72 hours) / 3

\section{Skin irritation/corrosion test}

In the case of skin irritation, $\mathrm{TiO}_{2}$ nanomaterial was known for mild or non-irritant to skin from the several studies using animals (guinea pig, rabbit) and 3D human skin model (KeraSkin ${ }^{\mathrm{TM}}$ ) [20]. In this study, Rabbits showed no irritation signs or skin reactions (oedema, erythema, eschar) in the test site applied with GST and P-25 of each rabbit at any observation time after removing patch applied with the test material on the skin lesion, respectively (Table 3, 4, Figure 7 and 8 ). The mean score was " 0.0 " and the GHS category was identified as a "No hazard class".

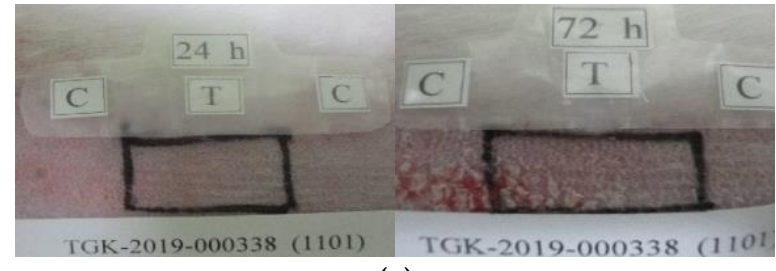

(a)

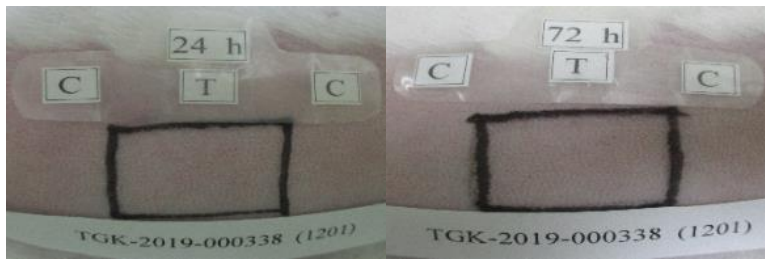

(b)

Figure 7. Skin photographs observed at 24, 72 hours after application of test substance, P-25 (No skin reaction): (a) Initial test; (b) Confirmatory test.

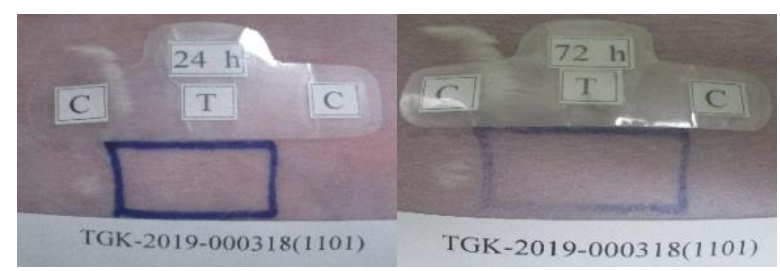

(a)

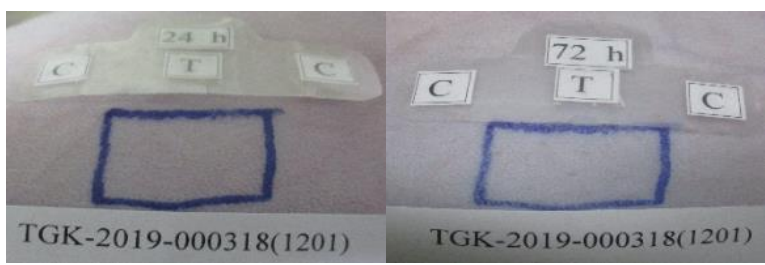

(b)

Figure 8. Skin photographs observed at 24, 72 hours after application of test substance, GST (No skin reaction): (a) Initial test; (b) Confirmatory test.

Table 3. Mean score of skin reaction (P-25)

\begin{tabular}{ccccc}
\hline Group & $\begin{array}{c}\text { Test } \\
\text { substance }\end{array}$ & $\begin{array}{c}\text { Animal } \\
\text { number }\end{array}$ & $\begin{array}{c}\text { Erythema and Eschar } \\
\text { Formation }\end{array}$ & Oedema Formation \\
\hline G1 & & 1101 & 0.0 & 0.0 \\
G2 & $\mathrm{P}-25$ & 1201 & 0.0 & 0.0 \\
& & 1202 & 0.0 & 0.0 \\
\hline
\end{tabular}

G1: Initial test, G2 : Confirmatory test, Mean score : $\sum$ Skin reaction (at 24, 48, 72 hours) / 3 
Table 4. Mean score of skin reaction (GST)

\begin{tabular}{ccccc}
\hline Group & $\begin{array}{c}\text { Test } \\
\text { substance }\end{array}$ & $\begin{array}{c}\text { Animal } \\
\text { number }\end{array}$ & $\begin{array}{c}\text { Erythema and eschar } \\
\text { formation }\end{array}$ & Oedema formation \\
\hline G1 & & 1101 & 0.0 & 0.0 \\
G2 & GST & 1201 & 0.0 & 0.0 \\
& & 1202 & 0.0 & 0.0 \\
\hline
\end{tabular}

G1: Initial test, G2 : Confirmatory test, Mean score : $\sum$ Skin reaction (at 24, 48, 72 hours) / 3

\section{Micro-CT analysis}

Micro-CT analysis was conducted to confirm the distribution of NPs in the eye and skin of rabbits treated with new $\mathrm{TiO}_{2}$ material (GST) to compare with those of control (eye: 1, 24 hours after treatment, skin: 1, 24 hours after removing patch).

In the eye applied with test substance, the residues of test substance were identified at 1 hour after treatment and showed no residues at 24 after the treatment site (right eye) in conjunctival sac site. Also, it was not observed inside or outside the eyeball and was the same observation as macroscopic observation of the conjunctival sac (Figure 9). The white spot observed at 1 hour in (Figure 9) was thought to be a residue after washing and these results were considered to be nonabsorption into the eyeball.

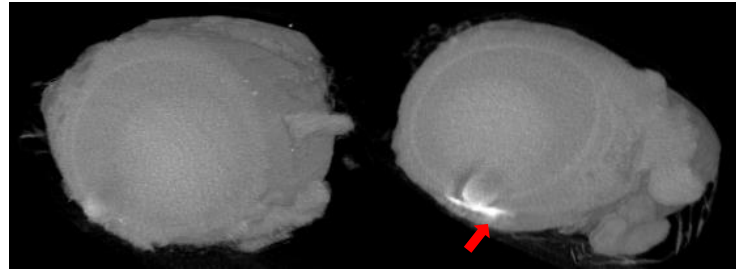

(a)

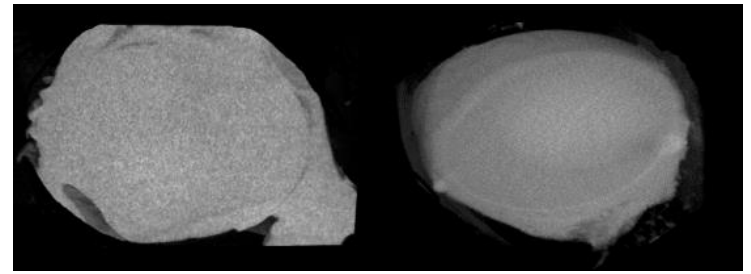

(b)

Figure 9. Eye micro-CT photographs (GST): (a) Eye photographs at 1 hours after application (Left: control, Right: test substance); (b) Eye photographs at 24 hours after application (Left: control, Right: test substance). *White spot: test substance, arrow: conjunctival sac site (red).

In the skin lesion applied with test substance patch, the test substance was observed on the skin treatment site at 1 hour after removing the patch, but no material was observed on or under the skin at 24 hours after removing patch (Figure 10). It meant that new $\mathrm{TiO}_{2}$ powder (GST) did not penetrate into the skin layer (under the epidermis) and the observed material was considered to be chemical residual on the skin treatment site.

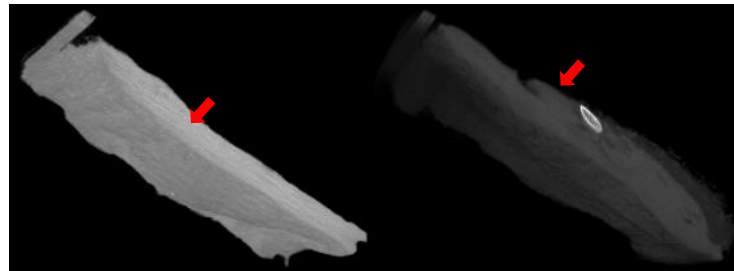

(a)

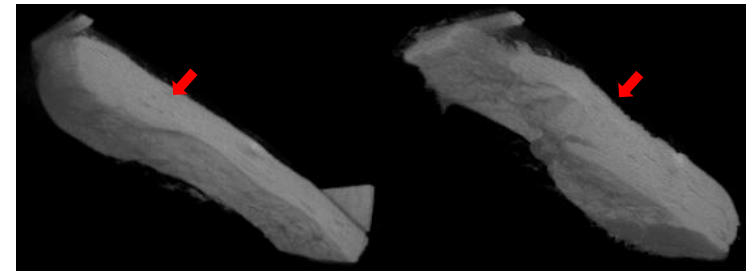

(b)

Figure 10. Skin micro-CT photographs (GST): (a) Skin photographs at 1 hours after removing patch (Left: control site, Right: test substance site); (b) Skin photographs at 24 hours after removing patch (Left: control site, Right: test substance site). *White: test substance, Red arrow: epidermis.

\section{Histology}

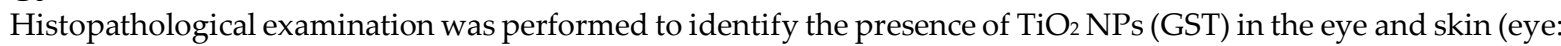
1, 24 hours after treatment, skin: 1, 24 hours after removing patch). The Figure 11 and Figure 12 showed that no substance was observed in the eye with accessory organ and skin and treatment-related effect was not examined at any observation time.

$\mathrm{Wu}$ et al. reported that no penetration of $\mathrm{TiO}_{2} \mathrm{NPs}$ of various particle size into the corneum of isolated porcine skin exposed for 24 hours in vitro [21]. Also, Study of Senzui et al. for damaged skin using tape stripping showed that the presence of $\mathrm{TiO}_{2} \mathrm{NPs}$ in hair follicles and no penetration was observed in the dermis or epidermis [22]. In our study, our histopathological examination for skin indicated that $\mathrm{TiO}_{2}$ NPs, GST did not penetrate into the skin layer (epidermis including stratum corneum/lucidum/granulosum/spinosum/basale). 
Kim et al. reported that histopathological finding showed the retinopathy in the eyes from animal treated with $\mathrm{ZnO}$ for 90 days and the presence of NPs was identified using micro-CT analysis method [11]. Considering this study, further study like repeated toxicity is thought to be needed to confirm whether presence or treatment-related effect for GST is observed or not.

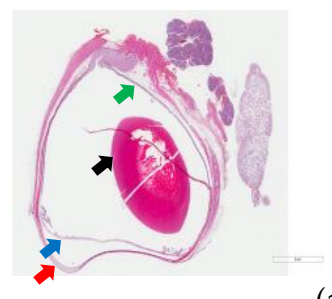

(a)

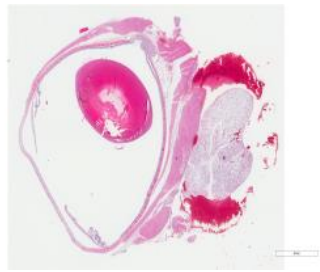

\section{(a)}

(b)

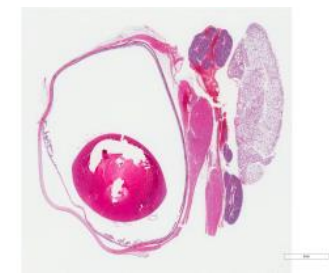

(GST):

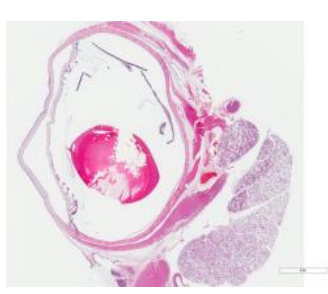
(a) Histological section of
of eye at 24 hours after eye at 1 hour after application (Left: control, Right: test substance); (b) Histological section of eye at 24 hours after application (Left: control, Right: test substance). ${ }^{*}$ Arrow: cornea (red), iris (blue), lens (black), retina (green).

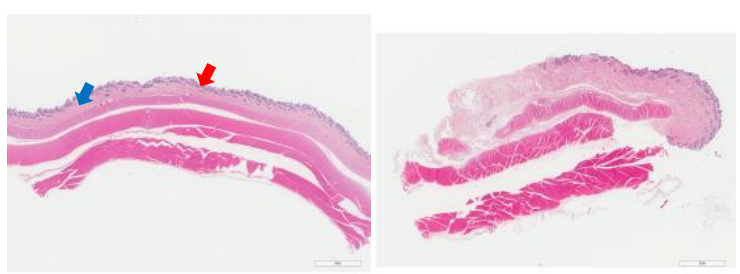

(a)

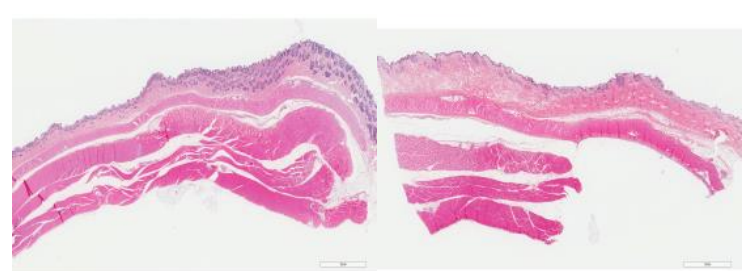

(b)

Figure 11. Skin photographs including epidermis, dermis and panniculus carnosus (GST): (a) Histological section of skin at 1 hour after removing patch (Left: control, Right: test substance); (b) Histological section of skin at 24 hours after removing patch (Left: control site, Right: test substance site). * Arrow: epidermis (red), dermis (blue).

\section{Conclusions}

Human exposure effect to $\mathrm{TiO}_{2}$ nanomaterial may occur when manufacturing and using many commercial products (cosmetics, paints, plastics, etc.). Also, major routes were known for inhalation and dermal exposure. Considering these points, eye or skin irritation/corrosion potential of the individual chemicals is needed for both hazard characterization and risk assessment when it is contacted on local lesions. The present study was performed to evaluate the effect of local lesions (eye, skin) for new $\mathrm{TiO}_{2}$ material, GST manufactured from sludge recycling of the sewage treatment plant. In addition to, the micro-CT and histopathological examination to investigate the location or distribution of local sites. As a result of the study, there was no irritation/corrosion of skin or eye, and the GHS category was identified as a "No hazard class". Also, no materials were observed on the local lesions and the treatment-related effect could not be evaluated in the lesions. Therefore, based on findings of local toxicity and imaging analysis, it was considered that GST had no irritation/corrosion and did not distribute in local lesions (eye, skin). Lastly more studies are needed to definitively comment on long-term use of new $\mathrm{TiO}_{2}$ (GST) material and health effects (for example, dermal repeated toxicity study, etc)

\section{Acknowledgement}

This work was supported by a grant (19SCIP-B145906-02) from the Korea Agency for Infrastructure Technology Advancement (KAIA) by Ministry of Land, Infrastructure and Transport of Korea government (MOLIT), Republic of Korea.

\section{Conflict of interest}

The authors declare that they have no conflict of interest.

\section{CRediT author statement}

SHK: Conceptualization, Methodology, Writing- Original draft preparation, MKP: Supervision, Writing- Reviewing and Editing, JKS: Methodology, Data curation, JMI: Visualization, HSP: Visualization, HSS: Visualization, HJP: Resources, SSN: Project administration, Writing- Reviewing and Editing 


\section{ORCID}

Sang Ho Kim: 0000-0002-4341-9915

Myeong Kyu Park: 0000-0003-3519-5867

Ja Kyung Seol: 0000-0001-9914-6250

Jae Min Im : 0000-0003-2288-2465

Hae Sung Park: 0000-0002-8393-9202

Heung Sik Seo: 0000-0002-4418-1646

Hee Ju Park: 0000-0002-2908-0898

Sung Soon Nah: 0000-0002-1875-5888

\section{References}

[1] Beer C, Stenderup K, Wang J, Sutherland DS, Nyengaard JR. Dermal absorption of nanomaterials titanium dioxide and zinc oxide based sunscreen. Environmen. Copenhagen K: The Danish Environmental Protection Agency 2015. https://doi.org/10.1007/s00204-015-1564-z.

[2] Smijs TG, Pavel S. Titanium dioxide and zinc oxide nanoparticles in sunscreens: focus on their safety and effectiveness. Nanotechnol sci and applica 2011;4:95-112.

[3] Zhang X, Li W, Yang Z. Toxicology of nanosized titanium dioxide: an update. Arch Toxicol 2015;89(12):2207-2217. https://doi.org/10.1007/s00204-015-1594-6

[4] Sadrieh N, Wokovich AM, Gopee NV, Zheng J, Hanies D, Parmiter D, et al. Lack of significant dermal penetration of titanium dioxide from sunscreen formulation containing nano- and submicron-size $\mathrm{TiO}_{2}$ particles. Toxicol Sci 2010; 115(1):156-166. https://doi.org/10.1093/toxsci/kfq041

[5] Bennat C, Muller-Goymann CC. Skin penetration and stabilization of formulations containing microfine titanium dioxide as physical UV filter. Int J Cosmet Sci 2000; 22(4): 271-83. https://doi.org/10.1046/j.1467-2494.2000.00009.x

[6] Shakeel M, Jabeen F, Shabbir S, Asghar MS, Khan MS, Chaudhry AS. Toxicity of Nano-Titanium Dioxide (TiO2-NP) through various routes of exposure: a Revew. Biol Trace Elem Res 2016; 172(1): 1-36. https://doi.org/10.1007/s12011-015$\underline{0550-x}$

[7] Park YH, Jeong SH, Yi SM, Choi BH, Kim YR, Kim IK, et al. Assessment of phototoxicity, skin irritation, and sensitization potential of polystyrene and TiO2 nanoparticles. Journal of physics 2011; 304(1);16-18. https://doi.org/10.1088/1742$\underline{6596 / 304 / 1 / 012050}$

[8] Simkó M, Mattsson MO. Risks from accidental exposures to engineered nanoparticles and neurological health effects: a critical review. Part fibre toxicol 2010;7(1):1-15. https://doi.org/10.1186/1743-8977-7-42

[9] Conway JR., Carragher NO. Timpson P. Developments in preclinical cancer imaging: innovating the discovery of therapeutics. Nat. Rev. Cancer 2014;14(5):314-328. https://doi.org/10.1038/nrc3724

[10] Schambach SJ, Bag S, Schilling L, Groden C, Brockmann MA. Application of micro-CT in small animal imaging. Methods 2010;50(1):2-13. https://doi.org/10.1016/i.ymeth.2009.08.007

[11] Kim YH, Kwak KA, Kim TS, Seok JH, Roh HS, Lee JK, et al. Retinopathy induced by zinc oxide nanoparticles in rats assessed by micro-computed tomography and histopathology. Toxicol. Res 2015;31(2):157-163.

https://doi.org/10.5487/TR.2015.31.2.157

[12] Gong JH, Joo JC, Kim JK. Preparation and characteristic evaluation of Low-cost $\mathrm{TiO}_{2}$ photocatalyst. J. Korean Soc Environ Eng 2019;41(4):196-203. https://doi.org/10.4491/KSEE.2019.41.4.196

[13] Hossain SM, Park MJ, Park HJ, Tijing L, Kim JH, Shon HK. Preparation and characterization of $\mathrm{TiO}_{2}$ generated from synthetic wastewater using $\mathrm{TiCl}_{4}$ based coagulation/flocculation aided with $\mathrm{Ca}(\mathrm{OH})_{2}$. J Environ Manage 2019;250:109521. https://doi.org/10.1016/j.jenvman.2019.109521

[14] Animal Protection Act. No. 16544 [enforcement, 2019-08-27] (2019-08-27, partial revision), Republic of korea

[15] Laboratory Animal Act. No. 15944 [enforcement, 2019-03-12] (2018-12-11, partial revision), Republic of korea

[16] OECD. Test No. 404: Acute dermal irritation/corrosion, OECD Guideline for the Testing of Chemicals, Section 4. Assessed on July 28, 2015. https://www.oecd.org/env/test-no-404-acute-dermal-irritation-corrosion-9789264242678en.htm 
[17] OECD. Test No. 405: Acute eye irritation/corrosion, OECD Guideline for the Testing of Chemicals, Section 4. Assessed on June 17, 2021. https://www.oecd.org/env/test-no-405-acute-eye-irritation-corrosion-9789264185333-en.htm

[18] Krstić M, Medarević Đ, Đuriš J, Ibrić S. Self-nanoemulsifying drug delivery systems (SNEDDS) and selfmicroemulsifying drug delivery systems (SMEDDS) as lipid nanocarriers for improving dissolution rate and bioavailability of poorly soluble drugs. In Lipid nanocarriers for drug targeting. William Andrew Publishing 2018; 473-508. https://doi.org/10.1016/B978-0-12-813687-4.00012-8

[19] Globally Harmonized System of classification and labelling of chemicals (GHS). United nations. New York and Geneva, Assessed in 2019.

https://www.unece.org/fileadmin/DAM/trans/danger/publi/ghs/ghs rev08/ST-SG-AC10-30-Rev8e.pdf

[20] Dréno B, Alexis A, Chuberre B, Marinovich M. Safety of titanium dioxide nanoparticles in cosmetics. J Eur Acad Dermatol Venereol 2019;33:34-46. https://doi.org/10.1111/jdv.15943

[21] Wu J, Liu W, Xue C, Zhou S, Lan F, Bi L, et al. Toxicity and penetration of $\mathrm{TiO}_{2}$ nanoparticles in hairless mice and porcine skin after subchronic dermal exposure. Toxicol Lett. 2009;191(1):1-8. https://doi.org/10.1016/j.toxlet.2009.05.020

[22] Senzui M, Tamura T, Miura K, Ikarashi Y, Watanabe Y, Fujii M. Study on penetration of titanium dioxide (TiO(2)) nanoparticles into intact and damaged skin in vitro. J Toxicol Sci 2010;35(1):107-113. https://doi.org/10.2131/jts.35.107 